\title{
EDUCAÇÃO PARA TODAS E TODOS: EM BUSCA DA EQUIDADE DE GÊNERO E DA DIVERSIDADE SEXUAL NO AMBIENTE ESCOLAR
}

\author{
EDUCACIÓN PARA TODAS Y TODOS: EN BUSCA DE LA EQUIDAD DE \\ GÉNERO Y LA DIVERSIDAD SEXUAL EN EL AMBIENTE ESCOLAR
}

\author{
Lindamir Salete Casagrande ${ }^{1}$ \\ Cíntia de Souza Batista Tortato ${ }^{2}$ \\ Marilia Gomes de Carvalho ${ }^{3}$
}

\begin{abstract}
Resumo
A necessidade de reflexão sobre as relações de gênero e diversidade sexual no ambiente escolar e a importância de se minimizar desigualdades e preconceitos nos levou a propor e realizar o curso de extensão universitária "Refletindo gênero na escola: a importância de repensar conceitos e preconceitos" cujos objetivos foram: 1- sensibilizar as/os profissionais da educação sobre a importância de se abordar as questões de gênero e diversidade sexual no ambiente escolar, e 2produzir conhecimento a partir desta experiência. O curso foi ofertado a profissionais do Município de Matinhos no Estado do Paraná - Brasil. O objetivo desta comunicação é apresentar os resultados de uma das atividades realizadas neste curso. Na referida atividade propôs-se às/aos participantes que fizessem uma pintura na qual fosse representada uma síntese dos conceitos e temas abordados no curso em questão. Elas e eles se reuniram em grupos e produziram obras que trataram sobre os mais variados temas como: a importância de se respeitar a diversidade de raça, classe, gênero e sexo; a necessidade de romper com estereótipos e preconceitos; a importância de se reconhecer e respeitar os diversos tipos de família existentes na sociedade brasileira; a necessidade de se oferecer uma educação democrática que busque a eqüidade de gênero, dentre outros. Nesta comunicação apresentar-se-á algumas obras produzidas juntamente com a explicação que as autoras deram e a interpretação que nós fizemos sobre as mesmas. Por meio desta atividade pôde-se perceber que as participantes assimilaram os conceitos e temas abordados no curso. Percebeu-se também a necessidade de se proporcionar outros momentos como este, visando minimizar os preconceitos e discriminações e evitar que diferenças de gênero se transformem em desigualdades sociais. Acreditamos assim, que a educação em todos os seus aspectos, inclusive no aspecto da inclusão e eqüidade de gênero é um direito de todos e todas e não um luxo.
\end{abstract}

Palavras-chave: Relações de Gênero no Ambiente Escolar; Diversidade Sexual; Profissionais da Educação.

1 Mestre em Tecnologia pelo Programa de Pós-Graduação em Tecnologia - PPGTE da Universidade Tecnológica Federal do Paraná - UTFPR, Curitiba, Paraná, Brasil. Professora da UTFPR e Pesquisadora do Grupo de Estudos e Pesquisas sobre Relações de Gênero e Tecnologia - GeTec. E-mail: lindasc@utfpr.edu.br.

2 Mestranda em Tecnologia pelo PPGTE/UTFPR. Pesquisadora do GeTec. E-mail: cintiatortato@hotmail.com.

3 Doutora em Antropologia Social pela Universidade de São Paulo - USP, professora do PPGTE/UTFPR, coordenadora e pesquisadora do GeTec. E-mail: mariliagdecarvalho@gmail.com. 


\section{Resumen}

La necesidad de reflexión sobre las relaciones de género y diversidad sexual en el ambiente escolar y la importancia de disminuir desigualdades y prejuicios, nos llevó a proponer y realizar el curso de extensión universitaria "reflexionando género en la escuela: la importancia de repensar juicios y prejuicios" cuyos objetivos fueron:1-sensibilizar a los profesionales relacionados a la educación sobre la importancia de plantear los temas de género y diversidad sexual en el ambiente escolar, y 2- producir conocimientos a partir de esta experiencia. La oferta de este curso fue para profesionales de la municipalidad de Matinhos en el estado de Paraná-Brasil. El objetivo de esta comunicación es presentar el resultado de una de las actividades realizadas en este curso. En tal actividad, se propone a los participantes que hagan una pintura en la cual se representase una síntesis de los conceptos y temas planteados en el curso. Se reunieron en grupos y crearon obras que tratan sobre temas variados como: la importancia de respetar la diversidad de razas, clase, género y sexo; la necesidad de romper con estereotipos y preconceptos; la importancia de reconocer y respetar los diversos tipos de familia existentes en la sociedad brasileña, la necesidad de ofrecer una educación democrática que busque la equidad de genero, entre otros. En esta comunicación se presentan algunas obras producidas junto a la explicación que las/os otras/os autoras/es dieron y la interpretación que hicimos sobre las mismas. Mediante esta actividad se puede notar que los participantes asimilaron los conceptos y temas planteados en el curso. Se percibió también la necesidad de proporcionar otros momentos como éste, con el objetivo de disminuir los prejuicios y discriminaciones y evitar que diferencias de géneros se transformen en desigualdades sociales. Creemos así, que la educación en todos sus aspectos, incluso en el aspecto de inclusión y equidad de género es un derecho de todos y no un lujo.

Palabras claves: Relaciones de género en el ambiente escolar; Diversidad sexual; Profesionales relacionados a la educación.

\section{INTRODUÇÃO}

A busca por uma sociedade mais democrática e justa tem sido um dos objetivos dos atores sociais que trabalham na escola (professores, professoras, alunos, alunas, supervisores, supervisoras, diretores, diretoras, enfim, profissionais da educação), para que sejam formados cidadãs e cidadãos que respeitem a diversidade cultural, os valores, as crenças, bem como os comportamentos relacionados à sexualidade. Assim, torna-se importante refletir sobre as questões de gênero no ambiente escolar, visto que, na escola encontra-se uma multiplicidade de indivíduos com experiências de vida, sonhos e realidades específicas e, compreender, aceitar e saber como lidar com esta diversidade é fundamental para quem busca uma sociedade mais justa, sem preconceitos e nem discriminações.

Pensando nisso, o Grupo de Estudos e Pesquisas sobre Relações de Gênero e Tecnologia - GeTec, do Programa de Pós-Graduação em Tecnologia - PPGTE da Universidade Tecnológica Federal do Paraná - UTFPR em parceria com o Grupo Interdisciplinar de Estudo, Ensino, Pesquisa e Extensão em Representações de Gênero e Diversidade - REGEDI da Universidade Federal do Paraná - UFPR campus Litoral e com a Prefeitura Municipal de Matinhos realizou o curso "Refletindo gênero na escola: a importância de repensar conceitos e preconceitos". O referido curso foi financiado pela Secretaria de Educação Continuada, Alfabetização e Diversidade - SECAD do Ministério da Educação - MEC. As aulas foram ministradas por pesquisadores do GeTec e do REGEDI a profissionais da educação do Município de Matinhos no litoral paranaense, no Brasil. Teve por objetivo sensibilizar as profissionais da educação sobre a importância de se abordar as questões de gênero e diversidade sexual no ambiente escolar. 
O curso foi dividido em quatro módulos, sendo que o primeiro módulo, com duração de $8 \mathrm{~h} / \mathrm{a}^{4}$, discutiu conceitos de gênero e diversidade sexual. O segundo módulo, que é objeto deste artigo, tratou das relações de gênero e diversidade sexual no ambiente escolar e teve duração de 16 h/a. No terceiro módulo, fez-se uma reflexão sobre gênero ciência e tecnologia em $8 \mathrm{~h} / \mathrm{a}$ e no quarto e último módulo, refletiu-se sobre gênero e diversidade sexual na mídia também com duração de $8 \mathrm{~h} / \mathrm{a}$, totalizado $40 \mathrm{~h} / \mathrm{a}$.

O curso foi destinado a profissionais da educação tais como, professores e professoras, diretores e diretoras, coordenadores e coordenadoras, merendeiras, zeladoras, pais que estivessem engajados nas atividades da escola e demais profissionais vinculados à educação. A participação foi predominantemente de professoras, porém todos, homens e mulheres, que participaram do curso mostraram estar abertos e dispostos a discutir a temática e a trabalhar para minimizar as desigualdades entre os gêneros e desenvolver o respeito à diversidade sexual no espaço escolar e fora dele. A maior participação feminina se justifica, pois, no Brasil, a maioria dos profissionais de educação do ensino fundamental são mulheres.

O objetivo do módulo 2 foi debater sobre as questões de gênero que se manifestam no ambiente escolar, buscando sensibilizar as participantes ${ }^{5}$ sobre a importância de tal reflexão para a construção de uma educação democrática e igualitária, visando a redução das desigualdades sociais e provocar indagações e inquietações nas participantes, levando-as à reflexão sobre as representações de gênero e suas relações na educação. Buscou-se também refletir sobre à necessidade de se desenvolver a cultura do respeito a diversidade sexual no espaço escolar ou fora dele.

Entende-se que a construção social e cultural da masculinidade e da feminilidade por meio das relações interpessoais e da interação das pessoas com o contexto no qual estão inseridas (COSTA, 1994). Estabelece relações de poder entre indivíduos do mesmo gênero ou de gêneros distintos (SCOTT, 1995) além de estar "relacionado fundamentalmente aos significados que são atribuídos ao ser mulher ou ao ser homem em diferentes sociedades e épocas" (FELIPE e GUIZZO, 2003, p. 121). Assim, não é um fenômeno fixo, tampouco unânime, está em constante mutação de acordo com as regras de convívio social de cada cultura. Durante o curso, foi ressaltada a importância dos atores sociais e das ferramentas utilizadas por estes com o intuito de facilitar o processo de ensino-aprendizagem para a construção e/ou manutenção das relações e representações estereotipadas de gênero.

A equipe responsável ${ }^{6}$ por este módulo decidiu que não iria limitar-se a exposição oral de conceitos, pois como o curso seria realizado nas sextas-feiras à noite a aos sábados pela manhã, as participantes estariam cansadas depois de uma semana de trabalho exaustivo em sala de aula e em seus lares e a aula expositiva seria cansativa, desta forma. Para o desenvolvimento do módulo optou-se pelo uso da metodologia participativa. Pensou-se em atividades que fossem lúdicas e que levassem à discussão dos conceitos e situações escolares com relação à eqüidade de gênero e diversidade sexual.

4 Abreviatura para horas/aula.

5 Neste artigo optamos por usar o feminino na escrita pois a grande maioria dos/as participantes eram mulheres.

6 O módulo que estamos abordando foi ministrado por Lindamir Salete Casagrande, Cíntia Souza Batista Tortato, Isis Moura Tavares, Beatriz Ligmanovski Ferreira e Maria Juracy Aires (pesquisadoras do GeTec), Stephanie Dahn Batista, Dione Tinti, Marcos Sergio Signorelli e Silvana Nonaka (pesquisadoras/es do REGEDI) 
Desta forma, utilizou-se de dinâmicas como brincadeiras, leitura de livros infantis, dentre outras para a introdução da temática e a produção de "obras de arte" e encenação com fantoches para a avaliação da assimilação dos conceitos por parte das participantes. Este artigo está baseado na produção das "obras de arte" das participantes do referido curso.

Para o desenvolvimento desta atividade, propôs-se que as participantes se reunissem em grupos de 4 ou 5 pessoas e produzissem uma obra utilizando-se de materiais como tinta, pincéis, canetas e papéis. Esta obra deveria resumir os temas abordados no curso até então. A atividade rendeu obras interessantes e algumas delas serão apresentadas a seguir.

\section{"Obras de arte"}

O objetivo desta atividade foi produzir uma síntese das atividades e dos $\operatorname{conceitos}^{7}$ abordados até aquele momento. Os grupos se dividiram de acordo com suas afinidades, sem a interferência das professoras e puseram sua criatividade em ação . As participantes demonstraram prazer e interesse nas atividades e os cartazes abordaram diversos temas como poderá ser observado nos que foram selecionados para apresentação neste artigo.

A FIGURA 1 mostra uma pessoa na qual não se pode identificar o gênero presa por meio de grades. As autoras da obra disseram que tiveram a intenção de representar à necessidade de se romper as grades que nos prendem a conceitos muitas vezes preconceituosos e ultrapassados. Essa ruptura pode ser feita por meio do conhecimento. Assim, as participantes ressaltaram a importância de se discutir a temática da busca

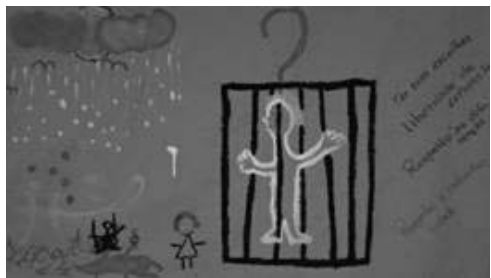

FIGURA 1: Prisão da mente Fonte: Foto Lindamir Salete Casagrande pela eqüidade de gênero e pelo respeito à diversidade sexual no espaço escolar e fora dele. A mudança das cores utilizadas no desenho como nuvem verde e árvore rosa indica a necessidade de mudança de paradigma e necessidade de abertura para diferentes formas de ver e viver a vida. O desenho vem acompanhado das frases "ter suas escolhas"; "liberdade de expressão"; "respeito às diferenças" e "respeito à individualidade". Esta imagem demonstra que as participantes compreenderam a necessidade de respeito ao próximo e a necessidade de estamos com os sentidos aguçados para perceber o que está ocorrendo a nossa volta.

Durante o encontro, as pesquisadoras que estavam coordenando a atividade ressaltaram a importância de se respeitar as diferenças, pois diferentes todos são e não há nada de errado nisso, entretanto, as diferenças de gênero, de raça, de orientação sexual, dentre outras não podem se transformar em desigualdade e motivo para discriminação. Ser diferente não significa ser inferior ou superior, tampouco ter menos ou mais direitos do que outros/as.

Este conceito parece ter sido bem assimilado, pois apareceu também na obra da

7 As discussões até o momento desta atividade tinham sido sobre as famílias, o respeito à diversidade sexual, a construção social do gênero, dentre outros temas. 


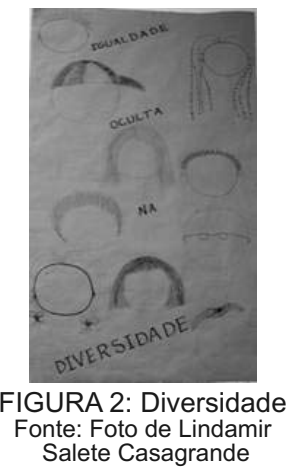

FIGURA 2. Nesta, as participantes escolheram uma parte do corpo para representá-la de diferentes formas. Esta parte foi a cabeça que foi desenhada com os mais variados tipos de cabelos. Foram omitidos propositadamente os olhos, o nariz e a boca para que fosse impossível saber se o rosto era de homem ou mulher, de menino ou de menina, pois segundo elas, isso não era importante. $\mathrm{O}$ importante seria o respeito que devia ser dispensado a todos da mesma forma.

A obra chamou bastante atenção das participantes e elas ficaram tentando identificar quais rostos seriam masculinos e quais seriam femininos. Esta reação do grupo demonstrou que mesmo estando debatendo a temática, mesmo sendo ressaltado que a diferença deveria ser respeitada, a idéia de se classificar as pessoas de acordo com determinados padrões ainda é forte e persistente. Evidentemente não se pretendia eliminar esta forma de pensar com poucos encontros, pois sabe-se que este é um processo gradativo e lento. O objetivo era sensibilizar os profissionais de educação para a temática,e pelo resultado apresentado nas obras realizadas pelas participantes, este curso representou um passo importante na longa caminhada para a desconstrução de padrões de gênero estereotipados.

O desenho vem acompanhado da frase "Igualdade oculta na diversidade" o que reforça a idéia de se respeitar a diversidade quer seja ela de gênero, raça/etnia, classe social, orientação sexual, religiosa, enfim, as diversidades. Sabe-se que as crianças do ensino fundamental têm o hábito de fazer piadas com as pessoas que são diferentes.

Nas escolas do Brasil, crianças que fogem ao padrão de "normalidade", ou seja, crianças que estejam abaixo ou acima do peso, que sejam muito altas ou muito baixas, usem óculos, tenham algum tipo de deficiência física, não se encaixem nos padrões de beleza eleitos pela maioria, que sejam consideradas "feias" sofrem com ironias, discriminações e piadinhas de colegas. Piadas que demonstram preconceito e que podem marcar as pessoas para o resto de suas vidas e até traumatizá-las.

Muitos relatos neste sentido foram feitos pelas participantes, alguns de experiência própria, preconceitos e discriminações que elas vivenciaram na infância e na adolescência. Outros relatos se referiam a situações que elas presenciaram no desenvolvimento de das atividades cotidianas no interior das escolas. Todos concordaram que os profissionais da educação devem estar preparados para combater esta prática das crianças no espaço escolar não com repreensão ou com castigos, mas sim com conversas, conscientização e atitudes que possam minimizar situações constrangedoras.

A diversidade também foi alvo de atenção da equipe que produziu a obra da

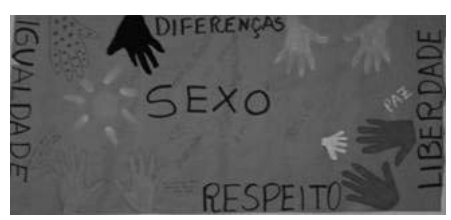

FIGURA 3: Mãos da diversidade Fonte: Foto de Lindamir Salete Casagrande FIGURA 3. O argumento das autoras desta obra foi semelhante ao das autoras da obra da FIGURA 2. Convém ressaltar que as obras foram produzidas em turmas diferentes e em diferentes épocas do ano o que demonstra que o argumento do respeito à diferença e à diversidade esteve presente nos diversos momentos.

Outro tema abordado foi sobre as transformações ocorridas na constituição da família. Em um determinado momento do curso leu-se o "Livro da Família" de Todd 
Parr. Nele, o autor apresenta de forma divertida os diversos tipos de família. Este livro foi utilizado para discutir a necessidade de se refletir sobre a constituição das famílias dos/as estudantes, principalmente em datas festivas como o dia dos pais e dia das mães. É uma prática comum nas escolas paranaenses se promover atividades em homenagem aos pais e as mães, porém muitas crianças não convivem com seus pois ou com suas mães e, nestes dias, sentem-se mal por não ter a quem homenagear.

Essa discussão foi representada na obra da FIGURA 4. Nesta figura pode-se ver uma família constituída por pai, mãe e filha; uma por pai e filha; uma por mãe e filha; e outra por duas mães e uma filha. A discussão acerca dos tipos de família foi importante e calorosa. Contou com a participação de todas e com o reconhecimento da necessidade de se refletir acerca da temática, entretanto, ficou evidente a dificuldade de romper

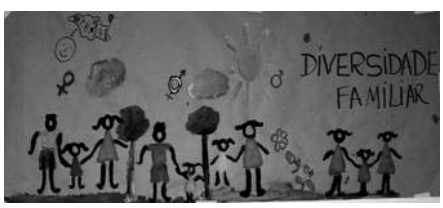

FIGURA 4: Diversidade familiar Fonte: Foto de Lindamir Salete Casagrande com a tradição de se comemorar o dia dos pais e o dia das mães. Segundo as participantes, existe uma cobrança por parte da sociedade para que estas datas sejam tratadas como momentos especiais.

Reconheceu-se que para uma criança que não tem mãe ou não tem pai muitas vezes é doloroso realizar as atividades propostas pelas professoras, porém elas ainda não encontraram uma alternativa para esta situação. Uma sugestão feita pelo grupo foi a de se comemorar o dia da família. Algumas acharam interessante outras não, pois acreditam ser importante ressaltar o papel do pai e da mãe na vida das crianças. Esta é uma questão que ainda necessita de muita discussão e reflexão para se chegar a uma solução que seja apropriada.

O grupo que produziu a obra argumentou que nas escolas esse assunto ainda divide bastante as opiniões, porém, em suas falas, concluíram que se a escola precisa aprender a considerar e respeitar modelos de família que foge ao tradicional, precisa também rever as formas de comemorar estas datas. Ressaltaram ainda a importância de incentivar a participação das famílias nas atividades comemorativas bem como nas demais atividades escolares.

Um relato importante foi o de uma professora de $2^{\mathrm{a}}$ série que contou ao grupo que sua turma negou-se a participar da atividade de dia dos pais proposta pela escola, argumentando que a maioria dos/as alunos/as não tinha pai presente em suas vidas, nem ninguém, que a seu ver, desempenhasse esse papel. A discussão proporcionou momentos de reflexão sobre os papéis dentro das famílias e as expectativas que os indivíduos criam em torno desses papéis. O grupo demonstrou uma certa inquietação, pois o assunto remete a realidade de muitas e não só das famílias dos/as estudantes.

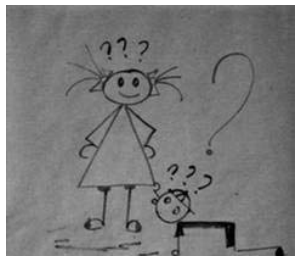

FIGURA 5: Curiosidade

Fonte: Foto de Lindamir Salete Casagrande

A FIGURA 5 é um desenho relativamente simples, porém significativo. Nele, o grupo que produziu a obra quis representar a curiosidade infantil. $\mathrm{O}$ grupo salientou que a curiosidade só existe por aquilo que não se conhece. Para eles a discussão acerca da sexualidade evitaria a "espionagem", pois se as crianças souberem o que há embaixo dos vestidos das meninas ou dos calções dos meninos elas não teriam tanta curiosidade em descobrir das formas mais diversas possíveis. Todas concordaram que é 
difícil falar sobre sexualidade com os/as filhos/as e principalmente com os/as alunos/as, porém necessário e importante. Muitas vezes, sexualidade é confundida com relação sexual ou com homossexualidade. Estas seriam razoes que dificultaria a abordagem da temática com as crianças.

Neste curso especificamente, sempre que se falava sexualidade, era como se as participantes ouvissem homossexualidade. Isso chamou a atenção das pesquisadoras responsáveis pelo módulo, pois representava a necessidade que elas tinham de falar sobre o assunto. Muitas relatavam casos de homossexualidade que elas conheciam e das dificuldades que essas pessoas enfrentavam para serem aceitas na sociedade e na família. As pesquisadoras responsáveis pelas atividades do módulo ressaltaram que sexualidade não é sinônimo de homossexualidade e é diferente de relação sexual dando ênfase à importância de se conhecer o próprio corpo para poder respeitá-lo. Este foi um tema que teve uma acalorada discussão e acredita-se que o resultado foi satisfatório.

Por outro lado, a Figura 5 pode ser lida de outra forma. Como aparece um menino "espiando" a menina, na visão desta equipe pode indicar que a curiosidade pelo corpo é mais presente nos meninos. $\mathrm{O}$ desenho mostra o menino ativo e curioso e a menina também curiosa, porém passiva. Esta obra reflete que os padrões de masculino (ativo, com iniciativa, curioso) e feminino (passiva, sem iniciativa, submissa) estão cristalizados e que só serão transformados com muita discussão e debate sobre a temática. Sabe-se que este é um processo lento, entretanto necessário e possível.

Na FIGURA 6, o grupo reproduziu um cenário com uma casa comum, um carro, uma árvore e personagens desenvolvendo as atividades corriqueiras. Entretanto, as autoras da obra inverteram os papéis colocando mulheres realizando as atividades tipicamente masculinas e homens nas atividades tipicamente femininas. $\mathrm{Na}$ imagem pode-se ver um homem limpando a casa e cuidando das roupas e uma mulher cuidando do carro, subindo na árvore, brincando com a pipa e pensando em aviões,

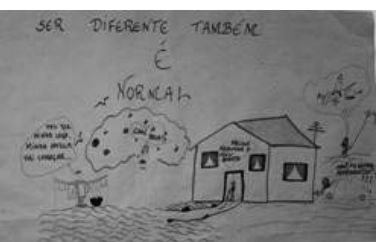

FIGURA 6: Inversão de papéis Fonte: Foto de Lindamir Salete Casagrande carros, foguetes. Segundo a equipe, elas quiseram representar neste desenho que o fato de homem e mulher se interessar por atividades comumente relacionadas ao sexo oposto não interfere na orientação sexual.

O desenho vem acompanhado da frase "ser diferente também é normal", pois segundo a equipe, o que está representado no desenho pode ser visto como diferente, entretanto não deve ser visto como problemático e tampouco gerar preconceito ou discriminação. No Brasil, um homem que realiza as atividades domésticas muitas vezes é vítima de chacota dos/as amigos/as e, para as autoras da obra, se for trabalhado desde a infância que não há nenhum problema em um homem realizar estas atividades, quando adultos, eles não terão dificuldade em assumir sua função dentro do lar e dividir com a mulher o cuidado com o lar e com os/as filhos/as.

A FIGURA 7 é diferente de todas as outras até aqui apresentadas. Ela não traz desenhos de pessoas e nem frases sobre as relações de gênero, entretanto a explicação feita pelas autoras da obra foi interessante. Para elas, a porta aberta representa uma infinidade de possibilidades, da mesma forma em que assumir uma postura sem preconceitos diante da vida e das outras pessoas, também abre uma infinidade de possibilidades de conhecimento e superação. Imaginando que a nossa vida, formada por 


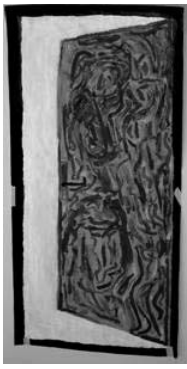

FIGURA 7: Porta entreaberta

Fonte: Foto de Lindamir Salete Casagrande

nossos valores e crenças, fosse como um ambiente fechado, a intenção foi abrir a porta, metaforicamente como se abre a mente e se muda a maneira de pensar. A porta também representa a liberdade de escolha, pensamento, expressão, ou seja, porta aberta para diferentes possibilidades. A porta aberta representa ainda a opção de posicionamento de cada um, pois ela está aberta, cabendo a cada um decidir se a atravessa ou não.

O medo do desconhecido, justificando muitas vezes a rejeição das pessoas ao que não conhecem, também foi ressaltado pelo grupo. A idéia do movimento também está representada na pintura de diversas formas. A posição aberta da porta representa um ir e vir, que segundo as autoras está relacionado às conseqüências de nossos atos (se alguém escolhe discriminar o/a outro/a pela sua cor, por exemplo, está sujeito/a também a uma reação deste/a outro/a, do seu grupo ou até a uma outra discriminação). As cores dos traços que decoram a porta sugerem a idéia de diversidade e igualdade, pois nenhuma sobressai e a beleza do conjunto está na união de todas elas. O grupo fez relações bastante complexas, facilitadas pelo fato de que uma das autoras da obra era artista plástica e tinha facilidades com essa forma de comunicação. A construção do argumento foi significativa e trouxe à tona diversos conceitos e preconceitos que foram abordados durante o curso.

\section{CONSIDERAÇÕES FINAIS}

O desenvolvimento desta atividade permitiu perceber que a maioria das participantes do curso estava preocupada em desenvolver uma educação que contemplasse a realidade da maioria das crianças que freqüentam as escolas públicas brasileiras. As participantes mostraram-se interessadas e preocupadas com a inclusão e o respeito à realidade de todas as crianças. Preocupavam-se também em desenvolver uma educação que minimizasse as desigualdades de gênero que buscasse integrar a todos no espaço escolar, independentemente da orientação sexual que a criança demonstrasse.

Percebeu-se que os conceitos abordados durante o curso foram bem recebidos e assimilados pelas participantes tendo em vista que boa parte deles foi representada nas "obras de arte" por elas realizadas. Aparentemente o conceito mais marcante foi o de respeito às diferenças e à diversidade, pois foi o mais representado.

As participantes mostraram-se ávidas pelo conhecimento e sentiu-se a necessidade de se proporcionar outros momentos como estes, para que a discussão sobre as relações de gênero, a busca pela eqüidade de gênero e o respeito à diversidade sexual dentro e fora do ambiente escolar, seja ampliado e difundido a um número cada vez maior de pessoas. Além do interesse que as participantes demonstraram pela temática, reforçaram a necessidade da busca por cursos que auxilie as professoras a abordar o tema com seus/suas alunos/as.

Esta atividade foi também eficiente como uma forma de avaliação do módulo. Avaliou-se a compreensão e assimilação dos conteúdos, satisfação e participação das alunas, sem que elas se sentissem avaliadas. 
Ao final do módulo solicitou-se que as participantes completassem três frases. O objetivo era avaliar a satisfação das participantes com as atividades, conteúdos e desempenho das pesquisadoras responsáveis pelo módulo. As frases eram "Que bom quê...", "Que pena quê..." e "Que tal se...". A avaliação das participantes foi mais positiva do que negativa. A maioria ressaltou a importância de se debater a temática, lamentou que o curso estivesse acabando e sugeriu que tivesse continuidade com outros momentos de discussão. Mesmo sendo um curso de final de semana, as participantes gostariam de ter mais encontros, com o intuito de buscar subsídios para que suas práticas docentes no interior das escolas sejam condizentes com uma educação mais igualitária e justa.

O curso evidenciou que a busca por uma educação mais igualitária, que acolha no espaço escolar a diversidade, que respeite as diferenças é um anseio das professoras. Para elas, a educação em todos os seus aspectos, inclusive no aspecto da inclusão e eqüidade de gênero é um direito de todos e todas e não um luxo.

\section{REFERÊNCIAS}

COSTA, Claudia de Lima. O leito do procusto. Cadernos Pagu, Campinas, p. 141-174, 1994.

FELIPE, Jane; GUIZZO, Bianca Salazar. Erotização dos corpos infantis na sociedade de consumo. Pro-Posições, Campinas, v. 14, n. 3 (42), p. 121-130, set./dez. 2003.

PARR, Todd. O livro da família. São Paulo: Panda Books, 2004.

SCOTT, Joan. Gênero: Uma categoria útil de análise histórica. Educação \& Realidade, Porto Alegre, v. 20, n. 2, p. 71-99, jul./dez,1995. 